\title{
Health professional networks as a vector for improving healthcare quality and safety: a systematic review
}

Frances C Cunningham, ${ }^{1}$ Geetha Ranmuthugala, ${ }^{1}$ Jennifer Plumb, ${ }^{1}$ Andrew Georgiou, ${ }^{2}$ Johanna I Westbrook, ${ }^{2}$ Jeffrey Braithwaite ${ }^{1}$

- Additional materials are published online only. To view these files please visit the journal online (http:// qualitysafety.bmj.com/ content/21/3.toc).

${ }^{1}$ Centre for Clinical Governance Research, Australian Institute of Health Innovation, University of New South Wales, Sydney,

Australia

${ }^{2}$ Centre for Health Systems and Safety Research, Australian Institute of Health Innovation, University of New South Wales, Sydney, Australia

Correspondence to Dr Frances C Cunningham, Centre for Clinical Governance Research, Australian Institute of Health Innovation, Level 1, AGSM Building, University of New South Wales, Sydney, NSW 2052, Australia;

f.cunningham@unsw.edu.au

Accepted 1 November 2011 Published Online First 30 November 2011

\section{(2) UNLOCK:1}

This paper is freely available online under the BMJ Journals unlocked scheme, see http://qualitysafety.bmj. com/site/about/unlocked. xhtml

\section{ABSTRACT}

Background: While there is a considerable corpus of theoretical and empirical literature on networks within and outside of the health sector, multiple research questions are yet to be answered.

Objective: To conduct a systematic review of studies of professionals' network structures, identifying factors associated with network effectiveness and sustainability, particularly in relation to quality of care and patient safety.

Methods: The authors searched MEDLINE, CINAHL, EMBASE, Web of Science and Business Source Premier from January 1995 to December 2009. Results: A majority of the 26 unique studies identified used social network analysis to examine structural relationships in networks: structural relationships within and between networks, health professionals and their social context, health collaboratives and partnerships, and knowledge sharing networks. Key aspects of networks explored were administrative and clinical exchanges, network performance, integration, stability and influences on the quality of healthcare. More recent studies show that cohesive and collaborative health professional networks can facilitate the coordination of care and contribute to improving quality and safety of care. Structural network vulnerabilities include cliques, professional and gender homophily, and over-reliance on central agencies or individuals.

Conclusions: Effective professional networks employ natural structural network features (eg, bridges, brokers, density, centrality, degrees of separation, social capital, trust) in producing collaboratively oriented healthcare. This requires efficient transmission of information and social and professional interaction within and across networks. For those using networks to improve care, recurring success factors are understanding your network's characteristics, attending to its functioning and investing time in facilitating its improvement. Despite this, there is no guarantee that time spent on networks will necessarily improve patient care.

\section{BACKGROUND}

Interest in networks as collaborating, professionalised structures continues to grow. As a post-bureaucratic form of organisation, ${ }^{1}$ networks have gained increasing popularity for governments and policymakers. With a considerable corpus of literature on networks within and outside the health sector, it is timely to assess the current state of knowledge, particularly in relation to how the features of networks may be applied to improve quality and outcomes of care. 'Network' is a word used extensively in healthcare research and in health services delivery. It is used as a synonym for 'partnership', 'collaboration', 'alliance' and 'group', or more specifically to describe the relationships between people, groups or organisations.

A 'social network' is a 'set of people or groups of people, "actors " ... with some pattern of interactions or "ties" between them ... [eg,] friendships among a group of individuals, business relationships between companies'. 2 There is a long history of examining social networks through network analysis techniques, with researchers focusing on structural and relationship properties. ${ }^{3-5}$ Social network analysis (SNA) can be used to examine structural relationships and influence in networks, the way information travels in networks, diffusion of innovative ideas, tools or practices, and sustainability of networks. It is the structure of networks and how the structural properties affect behaviour that is informative, not simply the characteristics of the network members. ${ }^{6} \quad 7$ Comprehensive reviews of the tools of SNA are provided by Knoke and Yang, ${ }^{8}$ Scott $^{4}$ and Wasserman and Faust. ${ }^{5}$ The online 
supplement (table S1) presents key SNA terms, along with their associated definitions, theories and propositions.

Work on the diffusion of medical innovations by Becker $^{9}$ and Coleman et $a l^{10}$ has confirmed the importance of local peer influences or social networks. While several reviews of social and organisational networks exist in the non-health sector literature, ${ }^{11-13}$ this review focuses on the health sector, in particular on health professional networks. Drawing from a literature review of complex socio-technical systems, Braithwaite et $a l^{14}$ argued for exploitation of natural network characteristics to achieve safer, better healthcare. Similarly, Parchman et al ${ }^{15}$ contend that efforts to understand the delay in adoption of evidence-based guidelines have been hindered by an overreliance on the attributes, knowledge, decision-making, and actions of individual clinicians, and an under-recognition of the network of care within which they operate.

Despite considerable progress in understanding what networks are, how they are structured, how they operate, and how they develop, we still know little about their effectiveness and sustainability in the health sector or their contributions to quality of care and patient safety. ${ }^{16}$ For example, Provan and Milward ${ }^{17}$ note the scarcity of comparative network data that are tied to outcomes, citing work by Lehman et $a l^{18}$ and Provan and Milward, ${ }^{19}$ while Provan and Kenis ${ }^{20}$ highlight the critical role of network governance and its impact on network effectiveness. This review examines the empirical research on the structure of networks of health professionals, with regard to the effectiveness and sustainability of networks, especially in relation to quality of care and patient safety.

\section{METHODS}

The systematic review was part of a broader review of the literature on social-professional networks of health professionals from 1995 to $2009 .^{21}$ This period was selected because most of the empirical work on health professional networks has been published since 1995, spurred on by advances in computing capacity and enabled through the development of SNA software. The search strategy (figure 1) obtained a subset of 26 articles bearing on network structure. The literature search was conducted between September and December 2009 using five electronic databases: MEDLINE, CINAHL, EMBASE, Web of Science (Science Citation Index, Social Science Citation Index, Arts \& Humanities Citation Index) and Business Source Premier (Management \& Business). Trial searches were undertaken with a number of additional electronic databases (LISA, Scopus, ABIInform-Global, IBSS, EconLit), however these did not yield additional papers and were not included in the search. We did not include the 'grey literature' as it did not meet the quality criteria of being peer reviewed and published in scholarly journals.

Following a preliminary review of terms in the literature, and of the MeSH database definitions of terms, key search terms were selected by the researchers to identify published research literature on social networks of health professionals (see online supplement, table S2). The key search term utilised was 'social network' for the initial search yielding 14607 articles. As the intent was to explore the literature relating only to social networks of health professionals, additional terms in this table were used to refine the search. To narrow the review to relevant material, a two-stage approach was used so that the articles generated from the first stage, the initial 'social network' search, were then examined in combination with each of the subsequent terms, in separate searches.

Search articles were reviewed to remove duplicates and incomplete references, yielding 1560 articles. The titles and abstracts were examined independently by two reviewers using inclusion and exclusion criteria. Under inclusion criteria, research had to focus in some depth on one or more aspects of networks of practising health professionals, or health agencies, particularly with relevance to quality of care and sustainability; that is, mere mention of the term 'network' was not sufficient. Other inclusion criteria included empirical research, peer reviewed, English language, scholarly journals, human and abstract and full text available. Exclusion criteria included articles on social networks of patients, clients or caregivers; health service networks (with no relevance to health professional practice relationships); non-health professionals (except for those working in the health system, health administrators or health policy makers); internet social networking; student-education processes; academic professionals or research scientists; infection control or epidemiological networks; bio-networks and neural networks; and e-health systems and software not relating to health professional practice.

This yielded 66 articles, obtained in full text for independent review by the two reviewers. By drawing on published checklists, ${ }^{22-25}$ quality was assessed according to the following: whether there was a clear and systematic description of the aim of the study, participants, sampling strategy, data collection and analysis methods, results of the study, relationship between the researchers and the participants, context and setting of the study, strengths and weaknesses, and implications of the study. (The study quality assessment criteria and ratings, the inclusion criteria and review process are set out in the online supplement: table S3 and boxes S1 and S2). Studies were excluded only after discussion among at least two reviewers, who assessed and agreed on the inclusion and quality rating of the studies. From this 


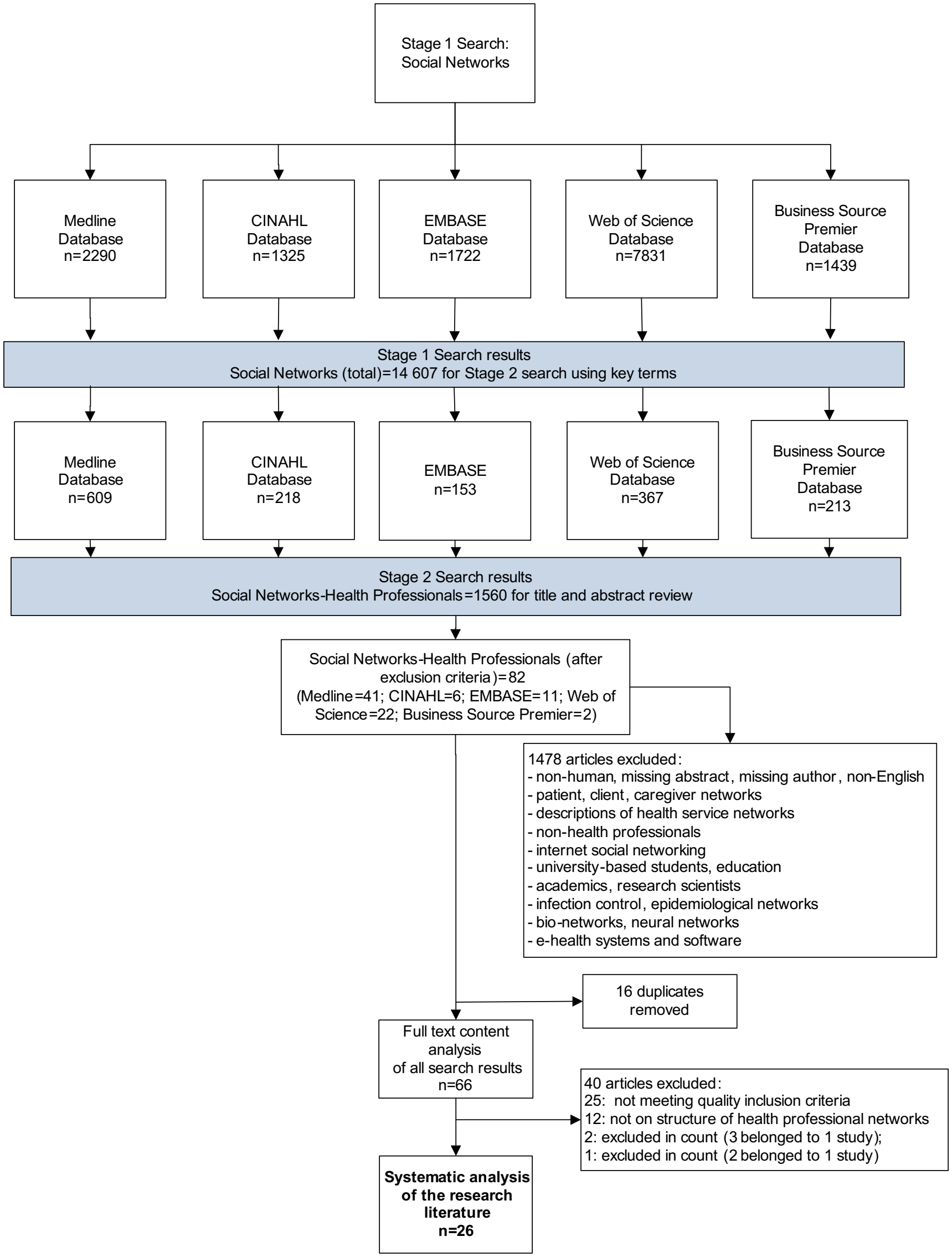

Figure 1 Flowchart of systematic review. 
sample we derived 26 articles with a focus on the structure of networks of health professionals, which met all the inclusion criteria and quality assessment criteria, and which were peer reviewed, empirical articles deploying recognised, clearly described research methods. Summary descriptive data from these studies were abstracted by one author (FCC) using a standard form to compile a tabular presentation of the study participants and setting, objective, design and method, and findings. All authors reviewed this documentation for accuracy and completeness. Full information was available within the articles reviewed without the need to contact study authors.

\section{RESULTS}

\section{Overview of studies}

The online appendix (table A) presents an overview of the 26 studies, including details of the study objective, participants, study dates, study context and findings. The online appendix (table B) also presents the research design and methodology of the studies, including a quality rating for each study, the data collection methods, sample size and response rate, and the type and level of analysis. Table 1 summarises the key study characteristics and table 2 presents the overall key structural findings relating to health network quality and safety. More than half (14) of the studies were published between 2004 and 2009. Half were undertaken in the USA, with hospital settings (11) representing the largest proportion. Of the 24 studies directed at health professionals, seven focused on multidisciplinary groups of clinicians, with others primarily studying single health professions (nine) or single health domain professionals (six). Four studies researched healthcare collaboratives or partnerships.

With respect to quality and safety, the studies have relevance to five of the six quality improvement dimensions identified by the Institute of Medicine, ${ }^{53}$ as indicated in the online appendix (table A, column 2): safe, ${ }^{30} 3134 \quad 3541-4349$ effective, ${ }^{26} 2833384547$ patientcentred, ${ }^{54}$ efficient, ${ }^{35} 394850-52$ and equitable. ${ }^{32}$ Timeliness was not addressed. Other aspects addressed by review studies with relevance to quality included culture, ${ }^{55}$ interdisciplinary teamwork, ${ }^{29}{ }^{36}$ service integration ${ }^{444647}$ and stability, ${ }^{33} 3447$ and diffusion of new practices. $^{27} 3740$

\section{Research design and analytical approach}

As detailed in the online appendix (tables A and B), two studies used ethnography, while the 24 quantitative studies included case studies, multi-case studies, and cross-sectional studies. Principal data collection methods included surveys (23 studies), interviews (4), ethnographic observation (2) and archival data collection (2).

\begin{tabular}{|c|c|c|}
\hline Characteristic & $\begin{array}{l}\text { Number } \\
\text { of studies }\end{array}$ & $\%$ \\
\hline \multicolumn{3}{|l|}{ Year } \\
\hline 1995-1999 & 7 & 27 \\
\hline $2000-2004$ & 5 & 19 \\
\hline 2005-2009 & 14 & 54 \\
\hline \multicolumn{3}{|l|}{ Country } \\
\hline USA & 13 & 50 \\
\hline Australia & 4 & 15 \\
\hline Canada & 3 & 12 \\
\hline UK & 2 & 7 \\
\hline Germany & 1 & 4 \\
\hline Italy & 1 & 4 \\
\hline Sweden & 1 & 4 \\
\hline Taiwan & 1 & 4 \\
\hline \multicolumn{3}{|l|}{ Setting } \\
\hline Hospital based & 11 & 42 \\
\hline Community health based & 7 & 27 \\
\hline $\begin{array}{l}\text { Primary and secondary care } \\
\text { health professionals }\end{array}$ & 4 & 15 \\
\hline Healthcare collaboratives & 2 & 8 \\
\hline Aged care & 1 & 4 \\
\hline Multi-disciplinary research institute & 1 & 4 \\
\hline \multicolumn{3}{|l|}{ Type of health professional } \\
\hline Multidisciplinary & 7 & 29 \\
\hline Mental health professionals & 5 & 21 \\
\hline $\begin{array}{l}\text { Health service managers or } \\
\text { administrative staff }\end{array}$ & 4 & 17 \\
\hline Nurses & 3 & 13 \\
\hline Medical practitioners & 2 & 8 \\
\hline Varied health professionals & 2 & 8 \\
\hline Dementia care professionals & 1 & 4 \\
\hline \multicolumn{3}{|l|}{ Study design } \\
\hline Multi-case study & 11 & 42 \\
\hline Case study & 8 & 31 \\
\hline Cross-sectional study & 5 & 19 \\
\hline Ethnographic case study & 2 & 8 \\
\hline \multicolumn{3}{|l|}{ Level of analysis } \\
\hline Actors and team & 3 & 12 \\
\hline $\begin{array}{l}\text { Actors and organisation } \\
\text { (or network) }\end{array}$ & 14 & 54 \\
\hline Organisation (or network) & 8 & 31 \\
\hline $\begin{array}{l}\text { Actors, organisation and } \\
\text { external network }\end{array}$ & 1 & 4 \\
\hline \multicolumn{3}{|l|}{ Data collection } \\
\hline Survey & 23 & 88 \\
\hline Ethnography & 2 & 8 \\
\hline Archival data & 2 & 8 \\
\hline
\end{tabular}

Most (19) used SNA to analyse data, with one study adding survival analysis, three studies using multiple regression, and two using other social science analyses. While 11 of the SNA studies had high response rates in the $90-100 \%$ range, the survey response rates varied from $100 \%$ or whole network samples ${ }^{39} 47$ to a low of $20 \%{ }^{38}$ The online appendix (table B, column 8) identifies the key aspects of network structure examined in each SNA study. 
Table 2 Key structural network findings for health network quality and safety

\begin{tabular}{|c|c|c|}
\hline Network feature & $\begin{array}{l}\text { Key structural findings for health network } \\
\text { quality and safety }\end{array}$ & Studies \\
\hline Brokerage & $\begin{array}{l}\text { Important in bridging connections and obviating } \\
\text { 'structural holes' in hospitals } \\
\text { Good coding performance is associated with } \\
\text { a knowledge sharing network structure rich in brokerage } \\
\text { and hierarchy, rather than density }\end{array}$ & $\begin{array}{l}\text { Heng et al (2005), }{ }^{26} \text { West and } \\
\text { Barron (2005), }{ }^{27} \text { Rangachari }(2008)^{28}\end{array}$ \\
\hline Centrality & $\begin{array}{l}\text { Centrality of key organisations or actors in a network is } \\
\text { important, and can be a strength or potential vulnerability } \\
\text { for network sustainability } \\
\text { Directors of nursing are more central in their networks } \\
\text { than clinical directors of medicine and their networks are } \\
\text { more hierarchical-hence better adapted to gathering and } \\
\text { disseminating information } \\
\text { The higher the centrality of the hospital in its network, } \\
\text { the better the hospital performance }\end{array}$ & $\begin{array}{l}\text { Cott (1997), }{ }^{29} \text { Creswick and } \\
\text { Westbrook (2007), }{ }^{30} \text { Creswick } \\
\text { et al (2009), }{ }^{31} \text { Gold et al (2008), } \\
\text { Lewis et al (2008), }{ }^{33} \text { Mendel et al } \\
\text { (2009), }{ }^{34} \text { Mossholder et al (2005), }{ }^{35} \\
\text { Webster et al (1999), }{ }^{36} \text { West and } \\
\text { Barron (2005), }{ }^{27} \text { West et al (1999), }{ }^{37} \\
\text { Peng et al (2006) }{ }^{38}\end{array}$ \\
\hline $\begin{array}{l}\text { Degrees } \\
\text { of separation }\end{array}$ & $\begin{array}{l}\text { Analysis of 'degrees of separation' can show the level of } \\
\text { connectivity in a professional network }\end{array}$ & Creswick et al (2009) ${ }^{31}$ \\
\hline Density & $\begin{array}{l}\text { The denser the GP network the lower the variation } \\
\text { in performance } \\
\text { Clinical directors of medicine are embedded in more } \\
\text { densely connected networks (cliques), than directors } \\
\text { of nursing, and can be stronger instruments for changing, } \\
\text { or resisting changes, in clinical behaviour. Networks of } \\
\text { directors of nursing have lower density, with advantages } \\
\text { in accessing information }\end{array}$ & $\begin{array}{l}\text { Fattore et al (2009), } \\
\text { West et al (1999), }{ }^{37} \text { West and } \\
\text { Barron }(2005)^{27}\end{array}$ \\
\hline Diffusion & $\begin{array}{l}\text { Ideological tension can block the spread of knowledge } \\
\text { and new work practices within the professional network } \\
\text { Gaps in the network of informal ties will impede the } \\
\text { dissemination of information and the spread of social } \\
\text { influence between nurse executives and physician } \\
\text { leaders, while non-clinical managers have a brokerage role }\end{array}$ & $\begin{array}{l}\text { Ormrod et al }(2007),{ }^{40} \text { West and } \\
\text { Barron }(2005)^{27}\end{array}$ \\
\hline Homophily & $\begin{array}{l}\text { People seek advice, or influence or discuss important } \\
\text { professional matters with those similar to themselves } \\
\text { (profession, gender, age, seniority), with implications } \\
\text { for communication exchanges } \\
\text { Physician leaders have more extreme homophily } \\
\text { than senior nurses }\end{array}$ & $\begin{array}{l}\text { Chase (1995), }{ }^{41} \text { Cott (1997), }{ }^{29} \\
\text { Creswick and Westbrook (2007), }{ }^{30} \\
\text { Creswick et al (2009), }{ }^{31} \text { MacPhee } \\
\text { (2000), }{ }^{42} \text { MacPhee and Scott (2002), } \\
\text { Webster et al (1999), }{ }^{36} \text { West and } \\
\text { Barron (2005), }{ }^{27} \text { West et al (1999) }\end{array}$ \\
\hline Hierarchy & $\begin{array}{l}\text { A large number of people in the network seek } \\
\text { information from particular individuals } \\
\text { For health professional teams other than medicine, } \\
\text { collaboration on problem-solving and decision-making } \\
\text { is limited to higher status professionals } \\
\text { Nursing networks are more hierarchical than } \\
\text { medical networks }\end{array}$ & $\begin{array}{l}\text { Creswick and Westbrook (2007), }{ }^{30} \\
\text { Cott (1997), }{ }^{29} \text { West et al (1999) }\end{array}$ \\
\hline $\begin{array}{l}\text { Integration } \\
\text { and cliques }\end{array}$ & $\begin{array}{l}\text { Relationships between groups of agencies, services } \\
\text { or providers (cliques) in a network may be more important } \\
\text { than the relationship between all agencies in the network } \\
\text { SNA can identify agencies and actors who are not well } \\
\text { linked in the network }\end{array}$ & $\begin{array}{l}\text { Calloway et al (1999), } \\
\text { Lemieux-Charles et al (2005), } \\
\text { Milward and Provan (1998), } \\
\text { West et al (1999) }\end{array}$ \\
\hline Multiplexity & $\begin{array}{l}\text { Employees forming a greater number of ties with } \\
\text { co-workers are more embedded and have lower turnover }\end{array}$ & Mossholder et al (2005) \\
\hline Network roles & $\begin{array}{l}\text { Individual roles in networks are important for } \\
\text { communication and information dissemination: } \\
\text { 'broker' and 'bridging' roles, 'cliques', 'isolates' }\end{array}$ & $\begin{array}{l}\text { Gold et al (2008), }{ }^{32} \text { Heng et al } \\
(2005),{ }^{26} \text { Mendel et al (2009), } \\
\text { Lewis et al (2008), }{ }^{33} \text { West et al } \\
(1999),{ }^{37} \text { West and Barron }(2005)^{27}\end{array}$ \\
\hline
\end{tabular}




\begin{tabular}{|c|c|c|}
\hline Network feature & $\begin{array}{l}\text { Key structural findings for health network } \\
\text { quality and safety }\end{array}$ & Studies \\
\hline Network stability & $\begin{array}{l}\text { Network stability is related to network effectiveness, } \\
\text { and can moderate the impact of resources } \\
\text { Longitudinal SNA can measure network expansion, } \\
\text { with decreased fragmentation increasing potential } \\
\text { information flow }\end{array}$ & $\begin{array}{l}\text { Milward and Provan (2003), } \\
\text { Mendel et al (2009) }\end{array}$ \\
\hline Reciprocity & $\begin{array}{l}\text { Reciprocity of ties shows whether there is a hierarchical } \\
\text { (low reciprocity) or horizontal (high reciprocity) structure } \\
\text { in the professional network }\end{array}$ & $\begin{array}{l}\text { Creswick and Westbrook (2007), } \\
\text { Creswick et al (2009) }\end{array}$ \\
\hline Social capital & $\begin{array}{l}\text { Organisational social capital, in addition to } \\
\text { professional experience and workload, can predict } \\
\text { overall job satisfaction } \\
\text { Social influence of peer professionals has a greater } \\
\text { impact than social capital on health professional performance }\end{array}$ & $\begin{array}{l}\text { Ommen et al (2009), } \\
\text { Fattore et al (2009) }\end{array}$ \\
\hline Social climate & $\begin{array}{l}\text { Positive social climate protects nurses against burnout } \\
\text { Professional and social networks and support do not } \\
\text { mitigate against work stress of chief manager nurses } \\
\text { or physician clinical directors }\end{array}$ & $\begin{array}{l}\text { Garrett and McDaniel (2001), } \\
\text { Lindholm (2006), }{ }^{50} \text { Lindholm } \\
\text { et al (2003), }{ }^{51} \text { Lindholm et al }(2004)^{52}\end{array}$ \\
\hline
\end{tabular}

Based on our quality assessment criteria (see online supplement, table $\mathrm{S} 3$ ), the quality ratings of the studies are provided in the online appendix (table B). Fourteen studies $(54 \%)$ were assessed as meeting all of the quality assessment criteria relevant to their study design. Ten studies $(39 \%)$ met almost all of the criteria, and those criteria that were not fulfilled were thought unlikely to alter the conclusions of the study. In two studies $(7 \%)$, some of the criteria were fulfilled, and those criteria that were not fulfilled were thought unlikely to alter the conclusions of the study. We did not include studies that met few or no quality assessment criteria.

The level of analysis is a key area of interest in network studies. There are three principal levels: the actor/s level, the network (or organisation) level and the internetwork (or inter-organisation) level. Seventeen studies were directed at two levels, the actors and the network (three looked at the actors and team), eight studies examined networks and one examined all three levels. Four main areas of structural relationships were studied: structural relationships within and between organisations; health professionals and social context; structure of quality collaboratives and healthcare partnerships; and structure in knowledge sharing networks. Table 2 summarises the key network features examined by individual studies, and identifies the substantive structural findings for health network quality and safety, in relation to those network features.

\section{Structural relationships within and between organisations}

Six studies examined structural relationships within and between networked organisations, including two of dementia provider networks, three of mental health provider networks (one comparing rural and urban relationships) and one of a hospital network. Carpentier et $a \check{l}^{4}$ used comparative case studies of seven organisations to examine relationships between the networks providing assistance to community patients with earlystage dementia in Montreal, Canada. The three interaction levels (interactions between practitioners and caregivers, internal structures and linkages between groups) were found to determine the quality of the practitioner-caregiver interface. Another Canadian case study on dementia care ${ }^{45}$ evaluated the effectiveness of four community-based dementia care networks in Ontario. SNA identified patterns of administrative and clinical exchanges among networked agencies. Exchanges between groups of agencies (cliques) within each of the four networks were more important than those between individual agencies within each network.

In seminal work examining network structure and effectiveness in the health sector, Milward and Provan ${ }^{46}$ used SNA to examine structural relationships in networks of provider organisations in two studies. The 1998 research included four city community mental health networks and one youth substance-abuse prevention network. Each of the four mental health networks was well integrated, based on two measures organisational links and cooperative links. With the substance-abuse prevention network, SNA helped to identify agencies not well linked to the system. Milward and Provan ${ }^{47}$ then used SNA on the results of the initial research, along with a 4-year study of one of the four networks, to evaluate collaboration and contracting strategies. The relationship between network structure and effectiveness was mediated by the context within which services were provided, with resource munificence and network stability identified as the two contextual 
variables. In the initial study, network stability moderated the impact of resources. In the 2003 study, an effective network was one with enough stability to maintain its ability to manage a set of jointly produced services.

Another study in a US mental healthcare setting ${ }^{44}$ used SNA to compare two rural and four urban care systems for people with severe mental disorders (SMDs). Both rural sites had numerous coordination linkages between the two types of provider groups (SMD and other service providers) for service planning and delivery. Density scores revealed the extent of service dependency when providers coordinated care to people with SMD in rural sites compared with urban sites. Service relationships among all specialised mental health providers were more likely to occur in rural than urban areas.

A study of chief executive officers in all accredited Taiwanese hospitals ${ }^{38}$ examined the impact of hospital resources, network resources and centrality on hospital performance. Hospital resources and centrality independently affected performance, whereas network resources did not. For that setting, the authors conclude that a hospital should improve performance by exploiting its in-house resources rather than obtaining network resources externally, and should occupy a central position to create a structural niche.

\section{Health professionals and social context}

Half of the studies (13) examined health professionals and social context, including six on work climate. Chase $^{41}$ used ethnography in two intensive care units (ICUs) in a US teaching hospital to analyse structure and communication patterns relating to the social context in which the process of critical care clinical judgement occurred from the nurse's perspective. With multiple clinicians involved in ICU patient-care decision-making, parallel hierarchies of nurses and of doctors allowed for checks on judgement both within and across professional lines. Also, rituals (nursing reports, physician rounds, flow sheet use) provided a context to check judgement processes.

Lurie et $a \tilde{l}^{5}$ applied SNA to three settings in one US clinical institution: team function in the ICU, the interdisciplinary composition of advisory committees, and relationships between key function directors. Researchers used SNA to compare teams on aspects of their clinical team functioning, and to show the degree of inter-disciplinarity of various clinical departments on the advisory committees. SNA identified potential problem areas with gaps in knowledge of functional roles among academic departments.

SNA was employed by Cott $^{29}$ to describe the structure of three multi-disciplinary, long-term care teams in a Canadian geriatric care facility. Effects of teamwork in sharing decision-making were limited to a group of higher status health professionals other than medicine, with the clearly defined hierarchy remaining for lower status sub-disciplines. Garrett and McDaniel ${ }^{49}$ conducted a cross-sectional study of five units in a US hospital to explore the relationships of environmental uncertainty, nurse characteristics and perceived work climate with professional burnout. Environmental uncertainty and perceptions of social-work climate were associated with burnout, yet findings suggested a positive social network climate could shield workers from the negative effects of crisis.

Mossholder $e t a l^{35}$ applied SNA and survival analysis to study healthcare employees in a large public US medical centre, examining whether structural, attitudinal and behavioural variables of a relational nature were predictive of employee turnover. Two variables, network centrality and interpersonal citizenship behaviour, predicted turnover with effects above and beyond the effects of job satisfaction. Workers forming more ties with coworkers (network centrality) became more embedded and had lower turnover, and higher interpersonal citizenship behaviour resulted in lower turnover.

A study of physicians in four German hospitals analysed the relationship between overall job satisfaction of physicians and social capital in the hospitals. ${ }^{48} \mathrm{Job}$ satisfaction was significantly associated with professional experience, and with lower workloads. The social capital of an organisation was a significant predictor of overall job satisfaction of physicians. In a similar research area, Swedish studies ${ }^{50-52}$ investigated whether psychosocial work conditions, professional network, job support, social network and support, sick leave and salary were associated with work stress in nurses in chief manager positions and physicians in clinical director positions. For both roles, a significant association was found between exposure to high job demands and a high level of work stress. Here, available psychosocial resources, inside and outside work, did not balance the experienced work stress in nurse managers and clinical directors exposed to high work demands.

The work of nurses with flexible and traditional schedules was compared in a US case study in an urban paediatric acute-care hospital. ${ }^{42}$ Applying SNA to examine the types of social networks used by both groups of nurses and to compare their workplace socialisation, no significant differences were found in the nurses' social network composition. However, traditional nurses used significantly more peer members for different types of emotional support. MacPhee and $\mathrm{Scott}^{43}$ also applied SNA to examine workplace social support networks of rural hospital nurses, compared with the urban nurse networks. Rural nurses' networks 
were predominantly peer based, but managers provided significant functional supports, with rural nurses expecting more guidance from management than urban nurses.

Ethnography was employed by Ormrod $e t a l^{40}$ in three UK NHS mental health clinics to examine how organisational practices were spread within networks of practice. Professional networks within psychiatry were found not to spread particular work practices equally to psychiatrists and their associated multi-disciplinary teams at two new sites. This was largely due to ideological differences in psychiatric practice approaches and differences in founder influence.

Webster $e t a l^{36}$ used SNA data on advice and social relations, to examine differences in eight mental health case-management teams in a Californian (USA) county mental health system. Male supervisors were substantially more central for 'instrumental' (advice) relations than female supervisors, displaying an autocratic leadership style. Male supervised teams were more centralised than female supervised teams. For the 'social' relations, male team supervisors were more central than female supervisors. Teams with female supervisors were more centralised than those with male supervisors, yet the female leaders were not the most central team member, showing a democratic leadership style.

Significant research on the professional social networks of clinical directors of medicine and directors of nursing in UK hospitals was undertaken by West et $a .^{37}$ Directors of nursing were more central in their networks than clinical directors of medicine, and their networks were more hierarchical. The networks of directors of nursing had lower density (having advantages in terms of access to information) than the clinical directors of medicine who tended to be embedded in much more densely connected networks (cliques). Doctors' networks were more egalitarian and decentralised than nurses' networks, hence change processes for the doctors need to involve group processes, rather than simply convincing individuals of the need to change.

In West and Barron's subsequent research, ${ }^{27}$ both directors of nursing and clinical directors of medicine discussed 'important professional matters' with others similar to themselves in terms of profession, gender, age, and seniority (homophily), with doctors being more extreme in this regard. Managers (non-clinically qualified) occupied a powerful brokerage role for both nurses and doctors, whereas nurses and doctors were rarely on each other's networks. Nursing and medicine had quite different social structures. With few informal ties between the two professions, information was unlikely to be spread between professions by informal sources.
Structure of quality collaboratives and healthcare partnerships

Four studies show the application of SNA in examining the structure and sustainability of collaboratives and partnerships. Gold $e t a l^{2}$ applied SNA to research relationships (structure and processes) among organisations participating in a large-scale, public-private, quality collaboration among major US health plans to reduce racial and ethnic disparities in healthcare. Sponsors and support organisations, along with a few of the health plans, formed the 'glue' holding the collaboration together. With limited communication among health plans, if the collaboration ended without greater communication among the non-core organisations, the absence of the core would leave a very sparse network. Gold et al advised collaborative sponsors to consider both short-term and long-term goals and whether they can be pursued if a collaborative ends.

Mendel $e t a \vec{l}^{4}$ used SNA to explore the numbers and types of inter-organisational partnerships within the US patient safety domain, the changes over time in these networks, and their potential for disseminating patient safety knowledge and practices. Between 2004 and 2006, partnerships grew in all activity domains, particularly dissemination and tools development, signifying growing strength in the capacity to disseminate and implement patient safety advancements. Fragmentation of the overall partnership network decreased, and potential for information flow increased. However, network centralisation increased, suggesting vulnerability to partnership failure if key participants disengaged.

SNA was applied by Lewis et $a l^{33}$ in a longitudinal analysis of network structure, dynamics and sustainability in primary care partnerships in Victoria, Australia at three time points between 2002 and 2005. Although network structures changed over the 3 years, there was the continuing centrality of the independent staff employed to manage the partnerships, with their crucial role in holding partnerships together. These partnerships required long-term support, not just start-up funding.

To study whether collaboration initiatives by a local health authority in Italy between 2001 and 2004 had any effect on individual and district-level general practitioner (GP) performance on drug expenditure targets, Fattore $e t a l^{39}$ used SNA. In terms of the GP's ability to meet expenditure targets, the social influence mechanism (the performance of peers to whom the GP was directly connected) was more relevant than the social capital mechanism (the centrality of the GP in the network). While collaborative arrangements induced more homogeneous behaviour among GPs, they did not necessarily improve the ability of GPs to meet local health authority objectives. 


\section{Structure in knowledge sharing networks}

The importance of homophilous behaviour was identified by Creswick and Westbrook ${ }^{30}$ who examined how a network of staff in an Australian hospital renal ward sought medication advice. Most communication occurred within professional groups. Similarly, a study of a network of staff in an Australian hospital emergency department by Creswick et $a l^{31}$ found that, when seeking advice, individuals were more closely connected to colleagues in their own professional groups. Heng $e t a l^{26}$ used SNA to explore the brokerage role of facilities management in an Australian hospital. Facilities managers actively bridged information and knowledge across different functions, filling structural holes within a communication network structure and being positioned to identify inter-disciplinary opportunities.

Although various studies discussed above identified features of network structure associated with better performance, Rangachari provided one of the few to link network structure with quality outcomes. ${ }^{28}$ This research in four large US teaching hospitals used SNA to explore the relationship between the organisational knowledge sharing structure related to quality, and hospital coding performance related to quality. Good-coding performance was associated with a knowledge sharing network structure rich in brokerage and hierarchy (with senior leaders coordinating knowledge exchange related to quality and connecting the organisation with the external environment), rather than density (with everyone connected to everyone else).

\section{DISCUSSION}

This review examined the empirical research on the structure of networks of health professionals, with regard to the effectiveness and sustainability of networks, especially in relation to quality of care and patient safety. There is a convergence of many networks, independent of their age, function and scope, to similar architectures. This has allowed researchers from different disciplines to embrace network theory as a common paradigm. ${ }^{56}$ Consistent with this theory, a number of the reviewed studies demonstrate the link between features of network structure and outcomes. Quality-related performance is associated with a knowledge sharing network structure rich in brokerage and hierarchy, rather than density. ${ }^{28}$ Social influence in a network is positively related to physician performance, ${ }^{39}$ social capital predicts overall job satisfaction, ${ }^{48}$ positive social climate protects employees against burnout, ${ }^{49}$ and employees with more co-worker ties have lower organisational turnover. ${ }^{35}$

The evidence demonstrates that creating cohesive, collaborative networks (of professionals or agencies) can pay dividends in coordinating care and attending to quality and safety issues and agendas. ${ }^{28} 3234394647$ The presence of key players, often in management or leadership roles, who act as connectors to transmit information, bridge disparate groups, liaise across parts of networks and enable social and professional interaction is vital. ${ }^{26} 27{ }^{32-34}$ They go by many names including mavens, connectors and bridges. In essence, they can facilitate communication and trust. ${ }^{27}$ However, the centrality of key players holding a network together can also be a vulnerability of such networks if they are relied on excessively and then leave, change roles or become marginalised. ${ }^{32} 34$

We have known for a long time that people naturally cluster together with those with whom they are comfortable: network theorists and sociologists call this homophily, and most people know this phenomenon as 'birds of a feather flock together'. ${ }^{29-31}$ Creating multidisciplinary or interprofessional teamwork within and across networks is thus a challenge. To address this challenge, active bridge building between subgroups across commonly occurring organisational divides (professions, genders and generations) is very important in creating larger, more resilient professional networks. ${ }^{26} 2736$ Strategies for quality improvement must address these factors, and the different characteristics of disciplinary networks (eg, nursing and medicine). ${ }^{27}$

As summarised in table 2, the characteristics of networks are important in facilitating greater levels of quality of care and patient safety. How far apart individuals are, for example, their degrees of separation, how central the key actors are, how intense the network relationships are, how dense the network is, how hierarchical relationships are structured and how stable the network is and the actors within it are all factors that will determine how well functioning the network will be and how well the actions of interacting agents will cohere to provide services. The received wisdom from various studies seems to be that being in an effective network which encourages communication and facilitates trust helps people feel good about their relationships, and to reciprocate positively with others to develop social capital. Positively functioning networks are likely to contribute more broadly to an effective organisational culture and climate. ${ }^{49-52} 57$ In this respect, networks can represent not just the social glue of professional interaction but the sociological building blocks of effective organisations.

Finally, we should ask what is missing from the research evidence we have uncovered and discussed. Although a third of the studies link network structure with evidence of outcomes, ${ }^{28} 35383947-50$ most of the research examines only the structural features of health professional networks. Using multi-method approaches, 
and exploiting advances in SNA, ${ }^{58}$ further well designed research should examine the relationships between professionals' network structures and health outcomes in a range of different care settings, and how the structural aspects of health professional networks can be leveraged to improve quality of care and patient outcomes. As to limitations, like all systematic reviews, this review is bounded by its scope and the range and quality of the research we have been able to uncover. The grey literature was not included as it did not meet study inclusion criteria. It is challenging to draw together the lessons to be learnt from disparate studies, even those that share a common focus and methodology.

\section{CONCLUSION}

On the basis of this review, for those participating in or supporting networks, the lessons are threefold. First, understanding the structure and characteristics of professional networks is vital, and second, it is important to attend to how they function. This leads to a third lesson: it may be time well spent, depending on local conditions, to nurture professional networks, and invest the time to facilitate their contributions to care. For example, recent work by Meltzer et $a \bar{l}^{5}$ demonstrates how SNA can assist in the design of effective quality improvement teams. The wellbeing of the organisation, the quality of services provided, and the collective efforts to deliver safe care to patients are likely to depend on such efforts. Spending time enabling networks is quite likely to be a useful pursuit for those intent on developing sustainable and well functioning organisations. However, this is not guaranteed and even if progress can be made, it is likely to be time consuming with no assurance that the investment in energy and effort will realise improved systems, cultures and delivery systems. Our review has shown, nevertheless, that existing research provides a foundation for a potentially fruitful yet underexplored research agenda in ascertaining the worth of networks in improving clinical care.

Acknowledgements We acknowledge the assistance, as second reviewer in the literature search, of Danielle Marks, Research Assistant, Centre for Clinical Governance Research, Australian Institute of Health Innovation, University of New South Wales, Sydney, Australia.

Funding This study was funded by the Australian Research Council Discovery Project (ARC DP0986493) and in part by the National Health and Medical Research Council Program Grant (NHMRC 568612). ARC: funder of this study as part of overall project; NHMRC: funder of c0-author, Jeffrey Braithwaite.

Competing interests None.

Contributors All authors contributed to the manuscript. Frances Cunningham, Jeffrey Braithwaite and Johanna Westbrook contributed to the overall conceptualisation and study design of the systematic review. All authors, Frances Cunningham, Geetha Ranmuthugala, Jenny Plumb, Andrew Georgiou, Johanna Westbrook and Jeffrey Braithwaite reviewed, contributed to and agreed on the systematic review methodology and the conduct of the review.
All authors contributed to writing the manuscript, and all authors have agreed on the final version of the manuscript.

Provenance and peer review Not commissioned; externally peer reviewed

\section{REFERENCES}

1. Heckscher C, Donnellon A. The Post-Bureaucratic Organisation: New Perspectives on Organizational Change. Thousand Oaks, California: Sage Publications, 1994.

2. Newman MEJ, Watts DJ, Strogatz SH. Random graph models. Proc Natl Acad Sci U S A 2002;99(Suppl 1):2566-72.

3. Freeman LC. The Development of Social Network Analysis: A Study in the Sociology of Science. Vancouver: Empirical Press, 2004.

4. Scott J. Social Network Analysis: A Handbook. 2nd edn. Newbury Park: Sage, 2000.

5. Wasserman S, Faust K. Social Network Analysis: Methods and Applications. New York: Cambridge University Press, 1994.

6. Burt RS. Structural Holes: The Social Structure of Competition. Cambridge, Massachusetts: Harvard University Press, 1992.

7. Coleman J. Foundations of Social Theory. Cambridge, Massachusetts: Belknap Press, 1990.

8. Knoke D, Yang S. Social network analysis. 2nd edn. Los Angeles: Sage Publications, 2008.

9. Becker $\mathrm{MH}$. Factors affecting diffusion of innovations among health professionals. Am J Public Health 1970;60:294-304.

10. Coleman JS, Katz E, Menzel H. Medical Innovation: A Diffusion Study. Indianapolis, Indiana: Bobbs-Merrill, 1966.

11. Borgatti SP, Foster PC. The network paradigm in organizational research: a review and typology. J Manage 2003;29:991-1013.

12. Brass DJ, Galaskiewicz J, Greve HR, et al. Taking stock of networks and organizations: a multilevel perspective. Acad Manage $J$ 2004;47:795-817.

13. Provan KG, Fish A, Sydow J. Interorganizational networks at the network level: a review of the empirical literature on whole networks. J Manage 2007;33:479.

14. Braithwaite J, Runciman WB, Merry AF. Towards safer, better healthcare: harnessing the natural properties of complex sociotechnical systems. Qual Saf Health Care 2009;18:37-41.

15. Parchman ML, Scoglio CM, Schumm P. Understanding the implementation of evidence-based care: a structural network approach. Implement Sci 2011;6:14-23.

16. Braithwaite J, Westbrook JI, Ranmuthugala G, et al. The development, design, testing, refinement, simulation and application of an evaluation framework for communities of practice and socialprofessional networks. BMC Health Serv Res 2009;9:162.

17. Provan KG, Milward HB. Do networks really work? A framework for evaluating public-sector organizational networks. Public Adm Rev 2001:61:414-23.

18. Lehman AF, Postrado LT, McNary SW, et al. Continuity of care and client outcomes in the Robert Wood Johnson Foundation program on chronic mental illness. Milbank Q 1994;72:105-22.

19. Provan KG, Milward HB. A preliminary theory of interorganizational network effectiveness: a comparative study of four community mental health systems. Adm Sci Q 1995;40:1-33.

20. Provan KG, Kenis P. Modes of network governance: structure management and effectiveness. J Publ Admin Res Theor 2007; 18:229-52.

21. Cunningham FC, Ranmuthugala G, Plumb J, et al. SocialProfessional Networks of Health Professionals: A Systematic Review. Sydney: Centre for Clinical Governance Research, Australian Institute of Health Innovation, University of New South Wales, 2010. http://www.med.unsw.edu.au/medweb.nst/page/ClinGov Monographs (accessed 19 Nov 2011).

22. Greenhalgh T, Taylor R. How to read a paper: papers that go beyond numbers (qualitative research). BMJ 1997;315:740-3.

23. Hill C, Spittlehouse C. What is Critical Appraisal? 2nd edn. Critical Appraisal Skills Programme: Hayward Medical Communications. February 2009. http://www.whatisseries.co.uk/whatis/pdfs/ What_is_crit_appr.pdf (accessed 23 Nov 2011).

24. Mays N, Pope C. Qualitative research: rigour and qualitative research. BMJ 1995;311:109-12.

25. Richardson WS, Detsky AS. Users' guides to the medical literature. JAMA 1995;273:1292-5.

26. Heng HK, McGeorge WD, Loosemore M. Beyond strategy: exploring the brokerage role of facilities manager in hospitals. J Health Organ Manag 2005;19:16-31.

27. West E, Barron DN. Social and geographical boundaries around senior nurse and physician leaders: an application of social network analysis. Can J Nurs Res 2005;37:132-48.

28. Rangachari $P$. Knowledge sharing networks related to hospital quality measurement and reporting. Health Care Manage Rev 2008;33:253-63. 
29. Cott C. 'We decide, you carry it out': a social network analysis of multidisciplinary long-term care teams. Soc Sci Med 1997; 45:1411-21.

30. Creswick N, Westbrook Jl. The medication advice-seeking network of staff in an Australian hospital renal ward. Stud Health Technol Inform 2007;130:217-31.

31. Creswick N, Westbrook JI, Braithwaite J. Understanding communication networks in the emergency department. BMC Health Serv Res 2009;9:247.

32. Gold M, Doreian P, Taylor EF. Understanding a collaborative effort to reduce racial and ethnic disparities in health care: contributions from social network analysis. Soc Sci Med 2008;67:1018-27.

33. Lewis JM, Baeza JI, Alexander D. Partnerships in primary care in Australia: network structure, dynamics and sustainability. Soc Sci Med 2008;67:280-91.

34. Mendel P, Damberg CL, Sorbero ME, et al. The growth of partnerships to support patient safety practice adoption. Health Serv Res 2009;44:717-38.

35. Mossholder KW, Settoon RP, Henagan SC. A relational perspective on turnover: examining structural, attitudinal, and behaviora predictors. Acad Manage J 2005;48:607-18.

36. Webster C, Grusky O, Podus D, et al. Team leadership: network differences in women's and men's instrumental and expressive relations. Adm Policy Ment Health 1999;26:169-90.

37. West E, Barron DN, Dowsett J, et al. Hierarchies and cliques in the social networks of health care professionals: implications for the design of dissemination strategies. Soc Sci Med 1999;48:633-46.

38. Peng TJ, Lo FY, Lin CS, et al. Benefiting from networks by occupying central positions: an empirical study of the Taiwan health care industry. Health Care Manage Rev 2006;31:317-27.

39. Fattore G, Frosini F, Salvatore D, et al. Social network analysis in primary care: the impact of interactions on prescribing behaviour. Health Policy 2009;92:141-8.

40. Ormrod S, Ferlie E, Warren F, et al. The appropriation of new organizational forms within networks of practice: founder and founder-related ideological power. Hum Relat 2007;60:745-67.

41. Chase SK. The social context of critical care clinical judgment. Heart Lung 1995;24:154-62.

42. MacPhee M. Hospital networking. Comparing the work of nurses with flexible and traditional schedules. J Nurs Adm 2000;30:190-8.

43. MacPhee M, Scott J. The role of social support networks for rura hospital nurses: supporting and sustaining the rural nursing work force. J Nurs Adm 2002;32:264-72.
44. Calloway M, Fried $\mathrm{B}$, Johnsen $\mathrm{M}$, et al. Characterization of rural mental health service systems. J Rural Health 1999;15:296-307.

45. Lemieux-Charles L, Chambers LW, Cockerill R, et al. Evaluating the effectiveness of community-based dementia care networks: the Dementia Care Networks' Study. Gerontologist 2005;45:456-64.

46. Milward HB, Provan KG. Measuring network structure. Public Admin 1998;76:387-407.

47. Milward HB, Provan KG. Managing the hollow state. Public Manag Rev 2003;5:1-18.

48. Ommen O, Driller E, Kohler $\mathrm{T}$, et al. The relationship between socia capital in hospitals and physician job satisfaction. BMC Health Serv Res 2009;9:81.

49. Garrett DK, McDaniel AM. A new look at nurse burnout: the effects of environmental uncertainty and social climate. J Nurs Adm 2001;31:91-6.

50. Lindholm M. Working conditions, psychosocial resources and work stress in nurses and physicians in chief managers' positions. J Nurs Manag 2006;14:300-9.

51. Lindholm M, Dejin-Karlsson E, Östergren PO, et al. Nurse managers professional networks, psychosocial resources and self-rated health. $J$ Adv Nurs 2003;42:506-15.

52. Lindholm M, Dejin-Karlsson E, Westin J, et al. Physicians as clinica directors: working conditions, psychosocial resources and self-rated health. Occup Med (Lond) 2004;54:182-9.

53. Institute of Medicine. Crossing the Quality Chasm: A New Health System for the 21st Century. Washington, DC: Institute of Medicine, National Academy of Sciences, Committee on the Quality of Healthcare in America, 2001.

54. Carpentier N, Pomey MP, Contreras R, et al. Social care interface in early-stage dementia: practitioners' perspectives on the links between formal and informal networks. J Aging Health 2008;20:710-38.

55. Lurie SJ, Fogg TT, Dozier AM. Social network analysis as a method of assessing institutional culture: three case studies. Acad Med 2009;84:1029-35

56. Barabási AL. Scale-free networks: a decade and beyond. Science 2009:325:412-13.

57. Braithwaite J, Hyde P, Pope C, et al. Culture and Climate in Health Care Organisations. Basingstoke, UK: Palgrave Macmillan, 2010.

58. Valente TW. Social Networks and Health. New York: Oxford University Press, 2010:233-7.

59. Meltzer D, Chung J, Khalili $P$, et al. Exploring the use of socia network methods in designing healthcare quality improvement teams. Soc Sci Med 2010;71:1119-30. 